\title{
Difficulties and Critical Success Factors for Implementing Industry 4.0 Technologies in the Continuous Process Chemical Industry
}

\author{
${ }^{1}$ Paulo Henrique Amorim Santos, ${ }^{1}$ Izabel Cristina Zattar, ${ }^{1}$ Robson Seleme \\ ${ }^{1}$ Federal University of Parana, Polytechnic Center - Administration, 81530-000, Curitiba, Brazil.
}

\begin{abstract}
Industry 4.0 technologies may provide great improvements in the productive environment of continuous chemical industries. For example, the availability of real-time data management improves unit operations integration in process intensification. This improvements provide increased profitability, safety, sustainability and fault prediction capability. However, the sector presents specific obstacles in deploying 4.0 technologies because of its intrinsic complexity. This paper objective is to identify the sector-specific difficulties and Critical Success Factors when implementing Industry 4.0 technologies. A comprehensive systematic literature review with content analysis was carried out. Among the emerging necessities identified, the need to simplify complex systems and intensify operations is highlighted. The literature also converges on the urgency for developing reliable systems for adverse event management and assessment models for health, safety and environmental management. This paper is therefore both a tool for managers who seek information when implementing 4.0 technologies and researchers who may be looking for new topics in this area. Future research opportunities in the area are also presented.
\end{abstract}

\section{Keywords: Industry 4.0; Chemical Industry; Continuous Processes; Critical Success Factors; Systematic Literature Review; Content Analysis.}

\section{Introduction}

The fourth industrial revolution is much more than a trend for automation. It is a set of new manufacturing practices that utilize the higher communication capacity and storage of large amounts of data, enabled by current technological advances. Industry 4.0 aims to develop models, methods and tools appropriate to the manufacturing industries (TIGOR et al., 2020;THOBEN et al., 2017) [1], [2] and is, therefore, characterized by the advancement of interactions between people, machines and resources, and the subsequent process decentralization (NGUYEN et al., 2020; MARTINS et al., 2018; HERMANN et al., 2016) [3],[4], [5].

The new technologies that follows Industry 4.0 are based on network communication and data management. Information can be obtained from a more volumous, fast and heterogeneous data (Big Data) to generate a virtual copy of the production facilities (PICCIONE et al., 2021) [6]. Cyber-physical systems (CPS) monitor the physical processes in real time, through sensors, actuators and simulators, increasing the process efficiency through decentralized decision-making (AITHAL, 2020; HERMANN et al., 2016; SHEVTSOVA et al., (2020) [5], [7], [8]. In addition, there is a integration of the production systems communicative elements (called the Internet of Things, or IoT) synchronized with the data processing generated by the CPS (SHEVTSOVA et al., 2020; KAGERMANN et al., 2013) [7], [9]. Industry 4.0 therefore proposes the adoption of an infrastructure capable of integrating a manufacturing production line intelligence in real time (NGUYEN et al., 2020; KUMAR et al., 2015) [4], [10]. Although Industry 4.0 still needs to better prove its benefits to society [11] (KOTYNKOVA, 2017), the number of recent publications on the subject is a indicator of its acceptance in the industry. This also shows the academia's interest in this promising evolution of the industrial environment. Deploying Industry 4.0, however, is often a complex project, presenting several obstacles that are characteristic of each manufacturing sector (CHIANG et al., 2017)[12] . The continuous chemical industry presents great potential for improvements in the new perspectives of Industry 4.0. For example, safe and efficient plant operation requires constant monitoring of thousands of process variables that nowadays are still attributed to human operators (SHU et al., 2016) [13]. Industry 4.0 technologies may help in reducing accidents and preserve the environment (CHRISTOFIDES et al., 2007) 
[14]. Recent works, like Chiang et al. (2017) [12] and Ji et al. (2016) [15] prove other specific benefits to the sector by using Big Data and CPS. Given current optimistic projections, it may seem surprising that there is still a lack of literature reconciling these new technologies to the chemical industry (CHIANG et al., 2017) [12]. However, this is partially explained obstacles in supply chain interfaces, which limit Industry 4.0 implementation (SCHLÖGL, 2017) [16]. To improve the field's current state-of-art, this article is guided by the following research question: "What are the difficulties and Critical Success Factors related to the deployment of Industry 4.0 technologies in the continuous process chemical industry?". This paper objective is to identify sector-specific difficulties and Critical Success Factors when implementing Industry 4.0 technologies. For this purpose, a comprehensive systematic literature review with content analysis was carried out, showing the sector evolution in the face of Industry 4.0 innovations. The study is therefore both a tool for managers to help implementing 4.0 technologies and a research agenda for academics who may be looking for new topics in this area.

\section{Research Design}

In order to perform our research, we had chosen Google Scholar and Scopus as scientific indexes due to their wider coverage. All searches were limited to English, Portuguese and Spanish language filtering, with no timespan specification. The definition of the search terms was based on the proposed theme, associating each segment of the continuous process chemical industry with industry 4.0 technologies. We constructed each search string by combining the main search term "Chemical Industry" and crossing 25 chemical industry segments with 19 terms commonly related to Industry 4.0 technologies, resulting in 475 search combinations. Table 1 shows the search terms used in the research.

Table 1: Search terms used in the research.

\begin{tabular}{|c|c|c|}
\hline \multirow[t]{10}{*}{ Main Search Term } & Segments & Technologies \\
\hline & "Fertilizers" & "Big Data" \\
\hline & "Industrial gas" & "Internet of Things" \\
\hline & "Petrochemical" & $\begin{array}{l}\text { "Industrial Internet of } \\
\text { Things" }\end{array}$ \\
\hline & "Plastic industry" & "Internet of Services" \\
\hline & "Resins" & \\
\hline & "Rubber" & "Cloud Computing” \\
\hline & “Elastomer", & $\begin{array}{l}\text { "Cyber-Physical } \\
\text { Systems" }\end{array}$ \\
\hline & "Synthetic fiber" & $\begin{array}{l}\text { "Additive } \\
\text { Manufacturing" }\end{array}$ \\
\hline & "Artificial fiber" & “Machine Learning”, \\
\hline \multirow{5}{*}{$\begin{array}{l}\text { "Chemical } \\
\text { Industry" }\end{array}$} & "Pesticides" & “Augmented Reality” \\
\hline & "Soap" & "Virtual Factory" \\
\hline & "Detergents" & “Digital Twins" \\
\hline & "Cleaning products" & $\begin{array}{l}\text { "Machine-to- } \\
\text { Machine"" }\end{array}$ \\
\hline & "Cosmetics" & "Human Machine \\
\hline
\end{tabular}




\begin{tabular}{|cc|}
\hline "Perfume" & Interaction" \\
"Hygiene" & "Radio Frequency \\
"Paints" & Identification" \\
"Varnish" & "Smart Cyber \\
"Polishes" & "Blockchain" \\
"Adhesive" & "Smart \\
"Explosive" & Manufacturing" \\
"Solvent" & "Industry 4.0" \\
"Dye" & "Smart Factory" \\
"Chlorine" & \\
"Alkali" &
\end{tabular}

The next steps taken to construct the final sample of articles considered in the systematic literature review and the content analysis are summarized in Figure 1.

Document search in the indexes, in accordance with the established criteria

$$
(n=10,173)
$$

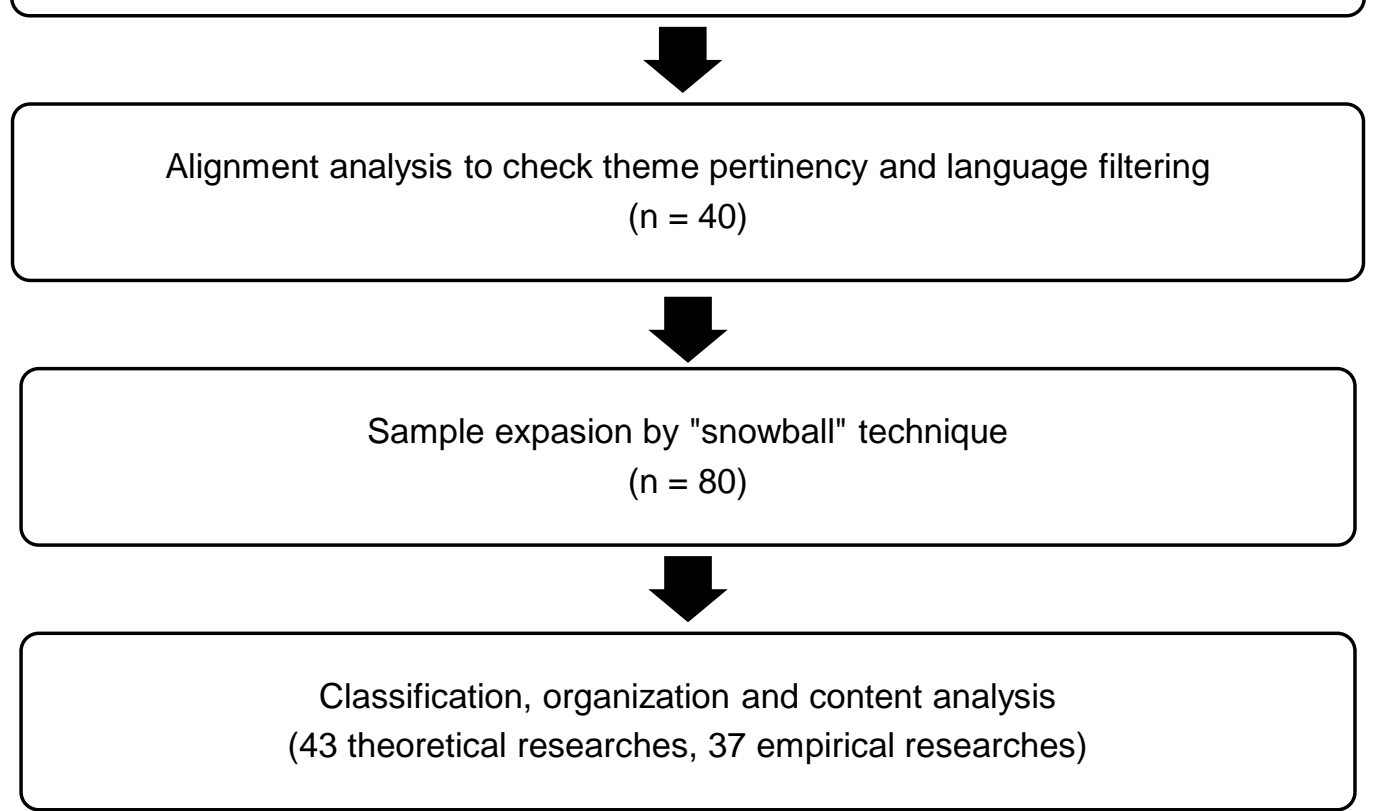

Figure 1: Systematic literature review and content analysis procedures

From the two scientific indexes, a total of 10,173 documents were considered for alignment analysis. From this initial sample, papers whose language was incompatible with the adopted criterion were disregarded. We also excluded publications whose title and abstract were not related to the theme. As a result, 40 papers were obtained that effectively related Industry 4.0 technologies to the continuous chemical industry. These papers were then subjected to the "snowball" procedure, which is a form of sample construction using bibliographic reference chains and is especially useful for studying certain areas that are difficult to access 
(VINUTO, 2014) [17]. Thus, it was possible to gather a final selection of 80 articles relevant to the theme. From this final sample, each publication was read in order to answer the proposed research question.

\section{Results and Discussion}

From the collected sample we identified both theoretical and empirical researches relating the perspectives of Industry 4.0 in the continuous chemical industry. For each article (whether theoretical or empirical), we conducted a content analysis searching for Industry 4.0 technologies related to the sector. This study revealed a greater trend of publications mentioning Big Data, the Internet of Things, Cloud Computing and Cyber-Physical Systems (see Figure 2). Together, these four technologies account for $67 \%$ of the occurrences.



Figure 2: Frequency of industry technologies 4.0 within the sample

To understand the role of these technologies in the sector we first discuss the development of Industry 4.0 by theoretical articles' perspective. Then, we analyse empirical cases to provide a more realistic view on the sector particular needs. Next, we compare general and specific challenges when deploying 4.0 technologies. Finally, the general and sector-specific Critical Success Factors are investigated.

\subsection{Theoretical Researches}

The analysis of theoretical publications reaffirmed the importance of the four technologies identified in Figure 1. For this sector, the need for new computational resources dedicated to the control process was already predicted by Ydstie (2002) [18], who believed that standardization in the communication system and simulation as a predictive analytical tool would be fundamental for the new information technologies. In this paper the author is firstly identified the integration of physics and communication networks as a futuristic perspective in chemical processes control. Following this publication, the number of theoretical publications exponentially increases, which can be understood as Industry 4.0 technologies gaining notoriety in the sector. Three years after the work of Ydstie, Grossmann (2005) [19] published an article that reached a greater visualization of the academic environment. The author identified the benefits to companies emerging from the interface of chemical engineering with operational research. Moreover, he asserted that the global market scenario would require new manufacturing technologies to preserve competitiveness.

With reference to both works, Christofides et al. (2007) [14] continued the research in collaboration with James Davis, who would become one of the most influent researchers in this area in the next few years. In 
"Smart Plant Operations: Vision, Progress and Challenges" the authors identified recent developments in process control, optimization and monitoring systems. In their conclusions, the authors emphasized the need for a coordinated research plan in this area and highlighted the lack of collaboration between academia and industry. In 2008, a workshop on manufacturing processes was held, sponsored by the National Science Foundation (NSF) and the Smart Process Manufacturing Engineering Virtual Organization (SPM-EVO). The workshop purpose was to foster further collaboration, focusing on the study of Industry 4.0 and creating a rationale for further research (EDGAR and DAVIS, 2009) [20]. After a period of few specific publications on Chemical Industry 4.0, Davis published "Smart manufacturing, manufacturing intelligence and demanddynamic performance" with the help of other collaborators (DAVIS et al. 2012) [21]. Over 30\% of the subsequent work relating Industry 4.0 and the chemical industry cited this article as a reference. It presented more mature conceptualizations and definitions, with a greater knowledge about the potential and limitations of the emerging communication technologies in manufacturing environments. Davis and Swink (2012) [22] also addressed systems that encompass commercial dimensions in comprehensive systems. With the help of other collaborators, the authors published an annual review on chemical and biomolecular engineering in 2015, focusing on the architecture and development of information technology infrastructure sought by Industry 4.0 [23]. This article is widely referenced by more recent publications.

Hao et al. (2015) [24] elaborate on a platform for integrating information on IoT and Cloud Computing technologies in the chemical industry. Thieven et al. (2016) [25] evaluated Industry 4.0's main applications in the different stages of chemical production. Inaba (2014) [26] presented an integration analysis of a refinery in a petrochemical complex. The study concluded on the need for a Big Data and IoT system to improve productivity and efficiency. García et al. (2017) [27] proposed vertical integration, which would allow access to data at lower cost. Khare and Chin (2017) [28] published the first identified work that used the term "Smart Chemical Industry". In the paper, the authors discussed the benefits of using efficient data collection as a source of knowledge. Wang et al. (2017) [29] focused on oil and gas storage and transportation facilities. The authors researched risk analysis and created a new management model from Big Data monitoring. Ge et al. (2017) provided a review of data mining and analysis applications in the process industry over the last few decades. He et al. (2017) [30] reviewed the state-of-the-art technology of cyber-physical systems. In addition, the authors explored the potential of sensors and IoTs for fabrication

\subsection{Empirical Researches}

In addition to the theoretical researches already presented we identified cases of practical application of Industry 4.0 technologies in equipment, simulations or whole industrial plants in the chemical sector. A content analysis of the sample showed the interplay between practical approaches of the technologies and each chemical segment, shown in Figure 3.

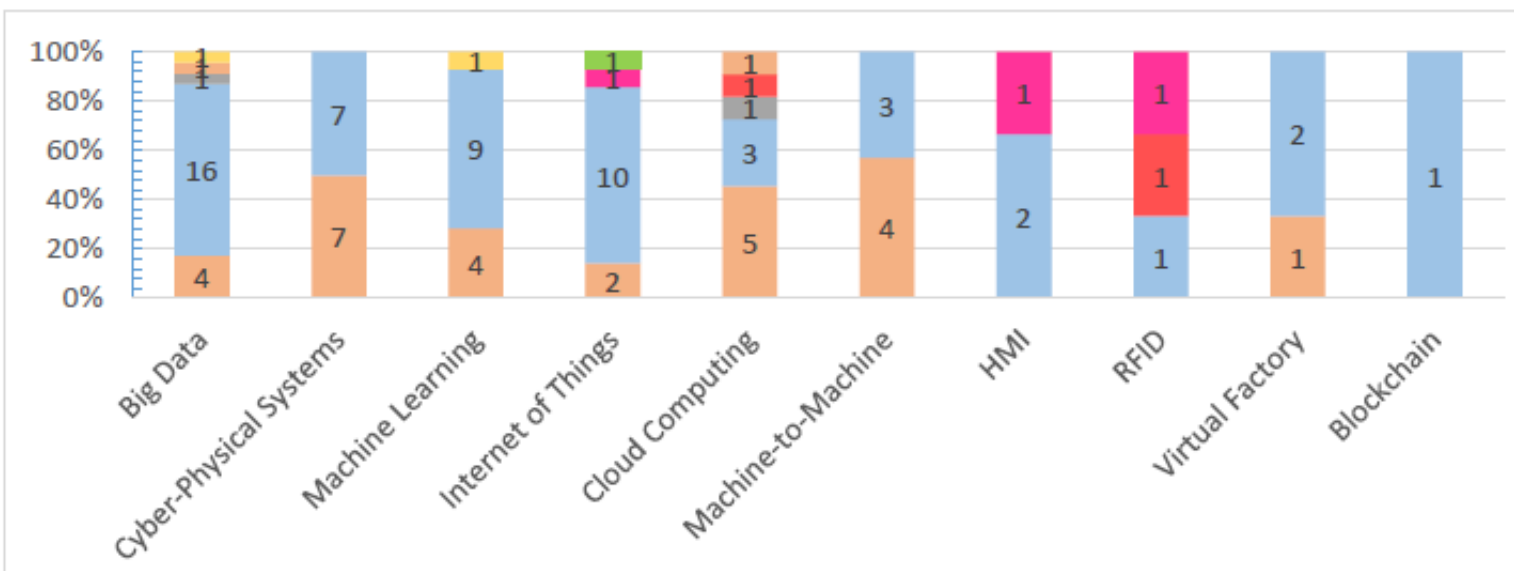

a Industrial gas $\square$ Petrochemical $\square$ Plastic industry $\square$ Paints $\square$ Adhesive $\square$ Soap $\square$ Solvent $\square$ Chlorine

Figure 3: Interplay between industry 4.0 empirical studies and chemical sector segments

Big Data technology is the one with the greatest number of industrial applications. This is partially explained by companies need to manage a large number of physico-chemical variables, which is a characteristic of the sector. It is possible to observe a predominance in the use of Big Data, Machine 
Learning and IoT by the petrochemical segment. Cloud Computing and Machine-to-Machine association with the production of industrial gases is also highlighted. CPS technology has applications in both of these segments. Big Data and Cloud Computing are also widely used by different segments. Other less frequent technologies, such as RFID and HMI, have already been applied in the industrial saponaceous manufacturing segment. The predominance of practical applications of Big Data, IoT, Cloud Computing and CPS technologies is consistent with the results presented with Figure 1. This is evidence of the sectors need to develop computational tools for data management. Following we discuss the role of each paper in this evolution.

In 2009, Greg Martin published the first work related to the chemical industry's application of 4.0 technologies: an analysis of the advantages of wireless internet technology in the petrochemical industry. The use of wireless internet allows availability of real-time information, new maintenance tools for equipment and improvements in security through remote access (MARTIN, 2009) [31]. The next application is found in Chang et al. (2011) [32] that implement a human-machine interface based on a small scale microprocessor and programmable logic, used in a biomass process, providing excellent supervision capacity. Davis et al. (2012) [21] also provides examples of applications of intelligent manufacturing in processes and supply chains. One of these examples was ExxonMobil, which built an outstanding information infrastructure in several of its units. Focusing on communication, management and security, the company made gains in planning its product portfolio. Natarajan et al. (2012) [33] et al. (2012) proposed a system called OntoSafe, that provides the possibility of managing abnormal situations. In 2014, the authors brought forward a proposal to apply this multi-agent architecture for the supervision of large-scale plants [54]. Another work in the context of management of abnormal situations in the chemical industry was that of Rathinasabapathy et al. (2016) [34], which developed a qualitative diagnostic methodology called the Causal Link Assessment (CLA).

More recent publications include Belaud et al. (2014) [35], which introduced a platform for the simulation, engineering, 3D visualization and management of Big Data for the chemical industry. Qin (2014) [36] is widely cited and proposes a definition of Big Data technology, describing its use and providing perspectives for the chemical process industry. Blackburn et al. (2015) [37] proposed a model for demand forecasting based on Big Data which proves to be superior to statistical methods, based on historical data from the BASF chemical industry. Squire and Song (2014) [38] presented two cases of successful implementation of cyber-physical systems in the chemical industry. Responding to technological progress, Ji et al. (2016) [15] discussed an intelligent chemical industry model based on CPS. Zhang et al. (2018) [39] presented a strategy to improve the operational agility of a refinery from Big Data and Fuzzy Logic.

Works regarding the petrochemical industry segment, in particular, were published in 2016 and 2017. Yuan et al. (2017) [40] and Hassani et al. (2017) [41] provided different views on the application of 4.0 technologies. Yuan et al. (2017) [40] gave examples of their application and Hassani et al. (2017) [41] identified the impact of technological innovation on the oil industry (such as cost reduction, time wasting reduction and efficiency gains). Hamzeh (2016) [42] investigated different methods of Big Data analysis used in the oil and gas industry, such as Hadoop ${ }^{\circledR}$, Microsoft ${ }^{\circledR}$ MURA, IBM ${ }^{\circledR}$ InfoSphere ${ }^{\circledR}$ and Oracle®.Also noteworthy is Kumar's doctoral thesis (2016) on methane reform, it being a complete work, in theory and experimentation. The work arises from Korambath et al. (2014) [43], where the authors developed a test prototype for a furnace temperature control model, by combining Cloud Computing and online service technologies. In Kumar's thesis (2016) [44], a control survey was presented on the temperature profile in an industrial methane reforming furnace. Infrared sensors that produce a large amount of data were used for this purpose. The management and utilization of this Big Data provided several positive results, including the implementation and monitoring of an Industry 4.0 computing infrastructure. The dissemination of his work with the collaboration of other researchers (mainly Michael Baldea and Thomas Edgar) inspired the publication of other articles on the subject. These resulted in a framework of sensors and models of Computational Fluid Dynamics (CFD) for the control of hydrogen production trials (KUMAR et al., 2016a) [45], a prediction model of furnace temperature distribution based on fuel (KUMAR et al., 2016b) [46] , the configuration design formulations for the improvement of furnace temperature distribution and valve actuation (KUMAR et al., 2016c) [47] and a multi-resolution model for plantwide operational optimization (KUMAR et al., 2016d) [48]. The technologies studied in his work concern Big Data, Cloud Computing, M2M, and a Virtual Factory. Korambath et al. (2016) [49] and Kumar et al. (2017) [50] were also published regarding the reduction of the energy cost of the process.

Paulo Henrique Amorim Santos, IJSRM Volume 09 Issue 07 July 2021 [www.ijsrm.in] EM-2021-2298 
Two papers stand out in environmental sustainability research. Pan et al. (2015) [51] proposed the implementation of Industry 4.0 in the design and optimization of Juron Island's eco-industrial park in Singapore. Kleinelanghorst (2017) [52] introduced J-Park Simulator (JPS), an eco-industrial virtualization that combines Machine-to-Machine (M2M) and mathematical modeling concepts to generate a design platform for eco-industrial parks. Sikorski, Haughton and Kraft (2017) [53] are the only authors to explore blockchain technology applications, proposing de-centralization as a safety measure for Machine-toMachine (M2M) interactions. Through the literature, it is possible to identify cases of the application of Big Data with Machine Learning technology (KUMAR et al., 2015) [10]. This is justified by the need for the continuous process chemical industry to automate the management of the large amount of physico-chemical data collected during the process. In addition, the two technologies can be used to ensure better safety protocols for adverse events (NATARAJAN and SRINIVASAN, 2014) [54].

The empirical papers and the respective Industry 4.0 technologies is shown in Table 3.

Table 3: 4.0 industry technologies in the continuous processes chemical industry.

\begin{tabular}{|c|c|}
\hline Technology & Author/ Year \\
\hline Internet of Things & $\begin{array}{l}\text { Martin, 2009; Wassick, 2009; Zuehlke, 2010; } \\
\text { Davis et al., 2012; Chung et al., 2014; Kumar et } \\
\text { al, 2015-2017; Kleinelanghorst et al., 2017; } \\
\text { Yuan et al., 2017; Hassani et al., 2017; Liu et al., } \\
\text { 2017García et al., 2017; Sikorski et al., } 2017\end{array}$ \\
\hline Big Data & $\begin{array}{l}\text { Wassick, 2009; Gao et al., 2009; Davis et al., } \\
\text { 2012; Natarajan et al., 2012; Belaud et al., 2014; } \\
\text { Blackburn et al., 2014; Windmann et al., 2015; } \\
\text { Pan et al., 2015; Kumar et al., 2015, } 2016 \text { (a; b; } \\
\text { c; d), 2017; Ji et al., 2016; Shu et al., 2016; } \\
\text { Hamzeh, 2016; Rathinasabapathy, 2016; } \\
\text { Korambath et al., 2016; Yuan et al., 2017; } \\
\text { Hassani, et al. 2017; Chiang, et al., 2017; Geng } \\
\text { et al., 2017; Leeuw, 2017; Zhang et al., } 2018\end{array}$ \\
\hline Cyber-Physical Systems & $\begin{array}{l}\text { Wassick, 2009; Davis et al., 2012; Natarajan et } \\
\text { al., 2012; Natarajan; Srinivasan, 2014; Squire; } \\
\text { Song, 2014; Pan et al., 2015; Kumar et al., 2015, } \\
\text { 2016 (a; b; c; d), 2017; Ji et al., 2016; Garcia et } \\
\text { al., } 2017\end{array}$ \\
\hline \multicolumn{2}{|l|}{ Cloud Computing } \\
\hline & $\begin{array}{l}\text { Belaud et al., 2014; Kumar et al., 2015, } 2016 \text { (a; } \\
\text { b; c; d), 2017; Shu et al., 2016; Korambath et al, } \\
\text { 2016; Yuan et al. 2017; Chiang et al., 2017; } \\
\text { Leeuw, 2017; Luo et al., } 2017\end{array}$ \\
\hline Radio-Frequency Identi & $\begin{array}{l}\text { Zuehlke, 2010; Chung et al., 2014; Luo et al., } \\
2017\end{array}$ \\
\hline Human Machine Interfa & $\begin{array}{l}\text { Zuehlke, 2010; Chang et al., 2011; Chung et al., } \\
\text { 2014; Rathinasabapathy, } 2016\end{array}$ \\
\hline Machine Learning & $\begin{array}{l}\text { Gao et al., 2009; Natarajan et al., 2012; } \\
\text { Natarajan; Srinivasan, 2014; Windmann et al., }\end{array}$ \\
\hline
\end{tabular}


Machine-to-Machine

Virtual Factory

Blockchain
2015; Kumar et al., 2015, 2016 (a; b; c; d), 2017; Kleinelanghorst et al., 2017; Korambath et al., 2016; Geng et al., 2017; Zhang et al., 2018;

Ragab et al., 2018

Kumar et al., 2015, 2016 (a; b; c; d), 2017;

Kleinelanghorst et al., 2017; Garcia et al., 2017;

Sikorski et al., 2017; Ragab et al., 2018

Kumar et al., 2015, 2016 (a; b; c; d), 2017;

Korambath et al., 2016; Kleinelanghorst et al., 2017

Sikorski; Haughton; Kraft, 2017

In order to better understand the processes of implementing those technologies, we compare in the next sections general and specific difficulties in the continuous chemical industry.

\subsection{General Difficulties in Implementing Industry 4.0 Technologies}

According to Piccione (2021) and Helu et al. (2015) [6], [55], the implementation difficulties of Industry 4.0 technologies can be grouped around resource and training requirements, cyber security risks, physical characteristics of the manufacturing environment, and standardization of software interfaces. For von Knop (2016) [56], Gezdur and Bhattacharjya (2017) [57] and Nguyen et al. (2020) [4], the deployment of 4.0 technologies demands cost, time and effort. Bogle (2017) [58], Yuan et al. (2017) [40], and Reitze et al. (2018) [59] affirmed that Industry 4.0 should be flexible regarding the market and its demand. Von Knop (2016) [56], Gezdur and Bhattacharjya (2017) [57], Isaksson et al. (2018) [60] and Bogle (2017) [58] add to this the need to adapt production to consumer desires. In this way, the companies' need to adapt their business models was confirmed (identified by Ydstie (2002) [18], Edgar and Davis (2009) [20] and Squire and Song (2014) [38]).

The literature is unanimous in identifying difficulties in managing, analyzing, and using the large amount of Industry 4.0 data. For many authors, this difficulty lies in obtaining robustness and reliability of the communicative systems (ZHOU et al., 2017; LIU et al., 2017; ISAKSSON et al., 2018) [60], [61], [62]. For Zhang et al. (2018) [39] , Yang (2018) [63] and Joly et al. (2018), the challenge was to ensure that the system responded in real time. In this sense, Yan et al. (2017) [64]added that another limiting factor is the communication capacity of the system, with band availability being a fundamental factor. Chiang et al. (2017) [12], Zhang et al. (2018) [39] and Joly et al. (2018) [65] confirmed the need for companies to have computational efficiency and broadband availability. Hermann et al. (2016) [5] and Qian et al. (2017) [66] further claimed that new technologies require the development of Human-Machine interfaces that facilitate user operation. Tigor et al. (2020) [1], Khare and Ching (2017) [28] and von Knop (2016) [56] and Chiang et al. (2017) [12] state that in order for this to happen, the development of specialized labor and technical assistance compatible with these innovations is necessary. According to the authors, given the complexity of the technologies of Industry 4.0, the required interdisciplinarity of the team must be high.

Another difficulty, identified by several authors, is coordination with the supply chain (BOGLE, 2017 [58] ; LEEUW, 2017 [67]; BALDEA et al., 2017 [68] ; ISAKSSON et al., 2018 [60]) [58], [60]. For this, it is necessary to ensure the connection and integration of the operations and software used by suppliers and customers (von KNOP, 2016 [56]; BALDEA et al., 2018 [68]). Thoben et al. (2017) [2] and Kusiak (2018) [69] agree that the standardizations required for machine connectivity and data integration are the major challenges encountered. In addition, the authors stated that ensuring cybersecurity is a continuing challenge. In this sense, the guaranteeing of cybersecurity was also identified by Christofides et al. (2007) [14] , Squire and Song (2014), Hermann et al. (2016) [5] and Bogle (2017) [58] and is a concern that accompanies the evolution of the fourth industrial revolution.

\subsection{Specific Difficulties for the Sector}


While there are similar challenges across many manufacturing sectors, there are specific difficulties for the continuous chemical industry (BOGLE, 2017) [58]. Ydstie (2002) [18] already predicted difficulties of technological innovation in the sector, the modeling and transcription of complex systems and the integration of control methods with the new information systems. Christofides et al. (2007) [14] identified the challenges as comprising the connectivity of the control elements, the real-time response, and the faultresponse system. In agreement with the authors, Bogle (2017) [58] affirmed that the technical challenges that confront the development of 4.0 technologies are related to robustness and security, the prediction of the properties of the mixtures, and new paradigms of modeling the chemical processes. Detailed modeling and transcription of systems should be done where possible and the development of new unit operations, products and measurement systems simplify complex systems, allowing process adaptation in the event of unavailability of data. The difficulties of 4.0 technology implementation were identified through content analysis and are shown in Table 4.

Table 4 - Difficulties in implementing Industry 4.0 technologies in the continuous processes chemical industry

Difficulties
Model and transcribe
complex systems

Authors / Year

Ydstie, 2002; Grossmann, 2005; Venkatasubramanian, 2008; Wassick, 2009; Zuehlke, 2010; Natarajan et al., 2012; Qin, 2014; Windmann et al., 2015; Kumar et al. 2015; Kumar et al., 2016; Li, 2016; Dai et al., 2016; Shu et. al., 2016; Bogle, 2017; Ge et al., 2017; Sun et al., 2017; Chiang et al., 2017; Yuan et al., 2017; Zhou et al., 2017; García et al., 2017; Liu et al., 2017; Zhang et al., 2018; Ragab et al., 2018; Baldea et al., 2018; Joly et al., 2018

Ydstie, 2002; Natarajan et al., 2012; Korambath et al., 2014; Rathinasabapathy et al., 2016; Yuan et al., 2017; Chiang et al., 2017; Baldea et al., 2017; Joly et al., 2018; Reitze et al., 2018

Christofides et al., 2007; Gao et al., 2009; Wassick, 2009; Li; Liu, 2010; Natarajan et al., 2012; Davis et al., 2012; Qin, 2014; Squire; Song, 2014; Luo et al., 2017; Windmann et al., 2015; Dai et al., 2016; Shu et. al., 2016; Rathinasabapathy et al. 2016; Chen et al., 2016; Bogle, 2017; Leeuw, 2017; Yuan et al., 2017; He et al., 2017; Liu et al., 2017; Yang, 2018; Ragab et al., 2018; Baldea et al., 2018

Create health, safety and environmental assessment models

Plant modifications and production interruptions

Develop new synthesis processes, intensify operations Christofides et al., 2007; Edgar, Davis; 2009; Natarajan et al., 2012; Belaud et al., 2014; Squire; Song, 2014; Luo et al., 2017; Dai et al., 2016; Li, 2016; Shu et. al., 2016; Bogle, 2017; Leeuw, 2017; Yuan et al., 2017; Khare; Chin, 2017; Qian et al., 2017; Liu et al., 2017; Edgar, Davis; 2009; Natarajan et al., 2012; Natarajan; et al., 2014; Squire; Song, 2014; Dai et al., 2016; von Knop, 2016; Leeuw, 2017; Khare; Chin, 2017; Baldea et al., 2018; Reitze et al., 2018; Isaksson et al., 2018;

Venkatasubramanian, 2008; Baldea et al., 2017; Bogle, 2017; Leeuw, 2017; Baldea et al., 2018; Reitze et al., 2018

and adapt products

Lack of deployment success cases

Christofides et al., 2007; Edgar, Davis; 2009; Montanus, 2016. He et al., 2017 
Modeling and transcribing complex systems: For Yuan et al. (2017) [40], the first challenge was to obtain reliable models for chemical processing units, especially for complex reactors. The complexity of mixtures and chemical reactions require the ability of mathematical models to consider numerous physicochemical properties (BOGLE, 2017) [58]. García et al. (2017) [27] confirmed that converting complex Big Data into operational decisions requires new data manipulation and analysis capabilities. Yuan et al. (2017) [40] also question whether the industry will trust and adopt the results of improvements. The reliability models of chemical systems have limitations under complex conditions. The large volume of data can overwhelm the capacity of the analysis system and adversely affect the efficiency of information processing (CHIANG et al., 2017) [12]. In addition to this, with the evolution of modern chemical processes, the information required for process supervision is distributed from several different sources, which requires effort in data management integration (NATARAJAN et al., 2012) [33].

Adapt classical control methods to new information systems: new control methods need to be developed and integrated into real operations at different scales under the effect of different physical phenomena in the chemical industry (YDSTIE, 2002) [18]. The combination of different data sources, to draw meaningful conclusions through Big Data analysis, is a difficult task (CHIANG et al., 2017) [12]. Korambath et al. (2014) [43] stated that the interaction between manufacturing operations and the various alternatives for the use of such information is an example of the challenges associated with deploying 4.0 technologies in the chemical industry. The industry requires new scalable digital platforms that upgrade the technology levels of current instrumentation (Yuan et al., 2017) [40].

Develop reliable fault response system for high risk processes: the diagnosis of industrial chemical plants is a difficult but necessary task (RATHINASABAPATHY et al. 2016) [34]. The challenge is to analyze the process data accurately and quickly so that corrective action can be taken in a timely manner (RATHINASABAPATHY et al. 2016). According to Bogle (2017) [58], hazard detection must be incorporated directly into the systems because operating close to ideal conditions often overloads the operations, resulting in a higher probability of failure. For Khare and Chin (2017) [28], the most important aspect in the chemical industry is safety. He et al. (2017) [30] argued that extracting useful information from Big Data is a significant challenge for monitoring process failure. Shu et al. (2016) [13] argued that although the concept of process failure diagnosis is an old research question, there are still only a few systems satisfactorily being applied in actual chemical processes.

Create health, safety and environmental assessment models: according to Mohan et al. (2021) and Liu et al. (2017) [62], [70], online health, safety and environmental management (HSE) is one of the most important requirements of Industry 4.0, as the consumer is increasingly interested in the industry's sustainability policies. The authors stated that system reliability is essential in the chemical industry. Shu et al. (2016) [13] reaffirmed that timely, reliable and automatic decision-making (which supports operations in abnormal situations in chemical processes), is an indispensable cognitive function for the chemical industry 4.0. According to Natarajan et al. (2012) [33], system reliability is one of the most important factors in assessing the health, safety and environmental state of the chemical industry as well as the likelihood of completing assigned tasks under certain conditions without failure. For Bogle (2017) [58], specific processes that are linked to health, safety, and the environment are critical, and must be properly modeled.

Modifications to plants and production interruption: The most important aspect in a continuous chemical industry is the maintenance of its maximum possible capacity (KHARE and CHIN, 2017) [28]. Natarajan et al. (2012) [33] mentioned that despite this, the physical structure of the continuous plant is constantly changeable. For example, certain sections of a plant may be removed for weeks or months for routine maintenance. Thus, mathematical models must be able to adapt to such changes (NATARAJAN et al., 2012) [33]. Edgar and Edgar (2009) [20] identified the main difficulty of the implementation of Industry 4.0 as being the interruption of production, which needs to be avoided in continuous processes. Since there is only rare quantitative evidence of the economic benefits of deploying 4.0 technologies, the authors also identified the need for research in phased deployment, where production disruption is minimized. Thus, change management needs to be maintained and documented, especially when it involves industry safety factors (SQUIRE and SONG, 2014) [38].

Unavailability of data: manufacturers face the challenge of improving the existing plants' capacity while reducing maintenance costs (KHARE and CHIN, 2017) [28]. According to Khare and Chin, both challenges have the need to obtain data through instrumentation and to analyse the ata available in real time in

Paulo Henrique Amorim Santos, IJSRM Volume 09 Issue 07 July 2021 [www.ijsrm.in] EM-2021-2302 
common. In addition, for complex systems which has data available on a smaller scale, reliability assessment models are vulnerable to system instability (LIU et al., 2017) [62]. Li and Liu (2010) [71] cited the low level of availability of information in the logistics of the chemical industry as an example. Hamzeh (2016) [42] added the difficulty of companies working with data from different sources.

Develop new synthesis processes, intensify operations and adapt products: Bogle (2017) [58] stated that one requirement of Industry 4.0 is the industry-to-consumer approach. In this sense, with the advancement of chemical process technology, there are possibilities of combining multiple operations in compact unit operations, intensifying the operational processes (BOGLE, 2017). Venkatasubramanian (2009) [72] identified opportunities for contributing to the fields of new chemical design, creation of specific infrastructures, data extraction systems, knowledge management environments and visualization of chemical processes.

Lack of successful deployment cases: the application of the Internet of Things to large numbers of sensors and data has not attracted much attention from researchers and industry professionals. One possible reason is that the benefits of such applications have not been recognized or tested (HE et al., 2017) [30]. Due to the novelty of Industry 4.0 and the lack of proven cases of usage, the operational and monetary benefits of the adoption of the elements of Industry 4.0 are still unclear (MONTANUS, 2016) [73].

\subsection{General Critical Success Factors in Implementing Industry 4.0 Technologies}

Critical Success Factors identification allows strategic focus on prospective and corrective actions that guarantee the development of a project (COLAUTO et al., 2004) [74]. For Gezdur and Bhattacharjya (2017) [57] it must take into account that digital transformation projects can require considerable time and effort. Critical Success Factors related to Industry 4.0 implementation includes the need for software connectivity and the standardization of communication between machines, integrated with the supply chain (YAN et al., 2017; IVEZIC et al., 2014 [75]; HELU and HEDBERG Jr, 2015; THOBEN et al., 2017) [2], [64], [75], [76]. Another important Critical Success Factors is the computational efficiency and availability of broadband (JUNG et al., 2015; LU, 2017) [77]-[79]. Since technologies are dependent on a digital platform and the wireless internet, real-time data transmission is dependent on this infrastructure. In relation to data management, the literature is convergent in affirming that there is a need to de-centralize analysis and the use of Big Data (LU, 2017; JUNG et al., 2015; O'DONOVAN et al., 2015; HELU et al., 2015) [55], [77], [79], [80]. In addition, the data store must be protected by a reliable cyber security system (HELU et al., 2015; KUSIAK, 2018) [55], [69].

As far as human resources are concerned, the deployment of 4.0 technologies are also dependent on trained and committed employees (HELU et al. 2015; CHOI et al., 2015; THOBEN et al., 2017 [2]; O'DONOVAN et al., 2015) [2], [55], [80], [81]. Jung et al. (2015) [77] and Lu (2017) [79] argued that a user-friendly interface between digital vehicles and operators is still required. Lu (2017) [79] and Helu and Hedberg (2015) [76] stated that there is a paradigm shift of production 4.0, focusing on consumer desire and demanding process flexibility in both market and demand.

\subsection{Specific Critical Success Factors for the Sector}

The general Critical Success Factors also applies for the chemical industry. Based on the development of Industry 4.0, $\mathrm{Li}$ (2016) [82] proposed the necessary resources in the petrochemical industry for the new industry: data management, real-time response, cyber security, specialized manpower and evolution of the Human-Machine interface. Qian, Zhong and Du (2017) [66] presented the three major critical factors within China's chemical industrial processes: describe the production process using accurate mathematical models, process optimization of a mixed, multi-objective approach, and a method for the optimization of production and management decision-making. For Hermann et al. (2016) [5], design principles for Industry 4.0 are: interconnection, information transparency, de-centralized decisions and technical assistance.

Besides those Critical Success Factors already mentioned, the content analysis conducted points to specific factors related to the sector, listed on Table 5 and discussed in sequence.

Table 5 - Specific Critical success factors for the continuous chemical industry

\begin{tabular}{|ll|}
\hline Critical Success Factor $\quad$ Authors / Year \\
\hline
\end{tabular}




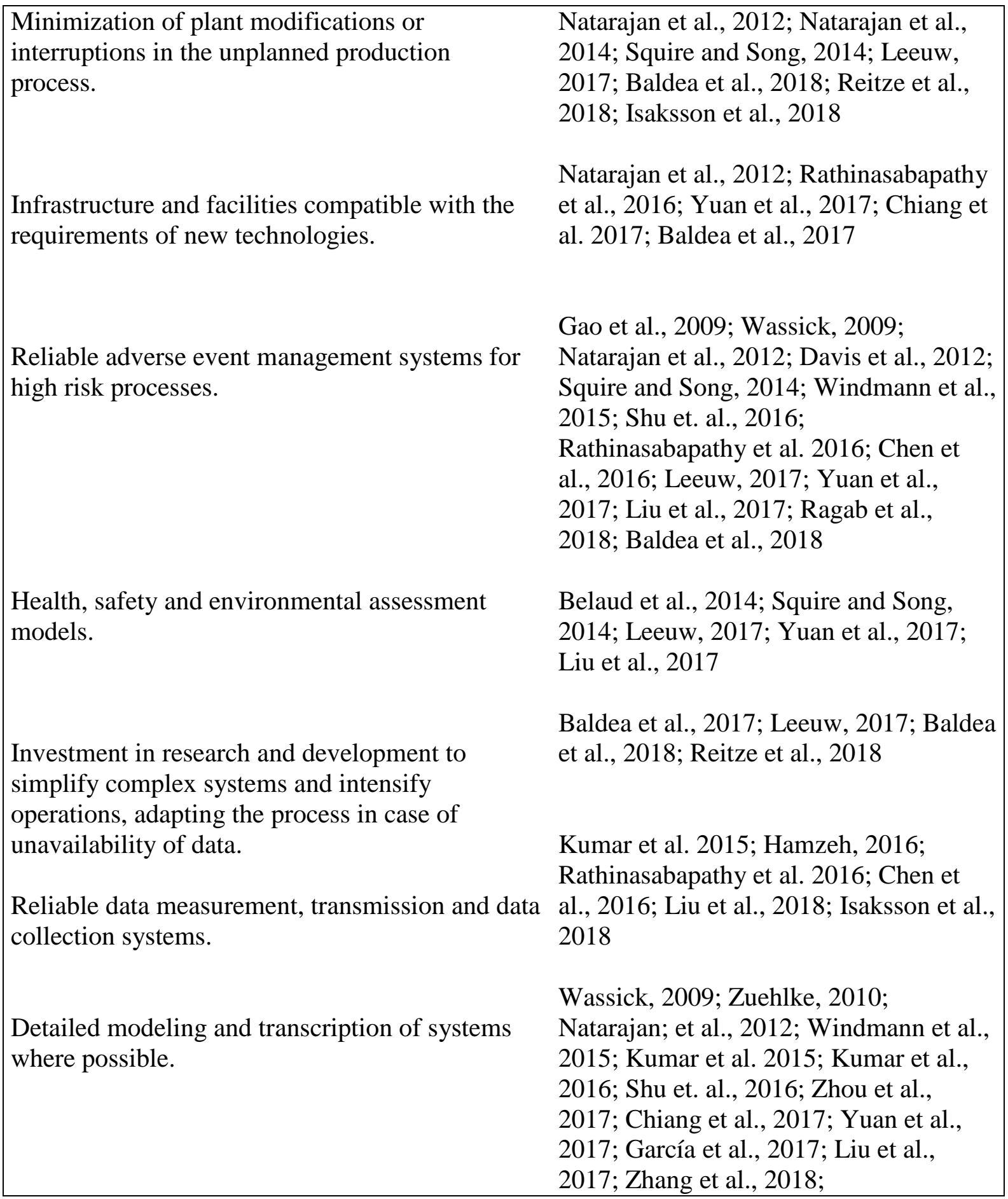

Minimization of plant modifications or interruptions in the unplanned production process: Liu et al. (2017) stated that the causes of many major accidents, such as those at Flixborough, Piper Alpha, and Petrobras ${ }^{\circledR}$, originated from changes in the process flow chart, equipment specification, and other key process descriptors. Thus, since the continuous chemical industry is under constant modification, the factory's control and safety systems must be constantly updated. Dai et al. (2016) concluded that any changes during operations should be reflected for the supervision of production in real time. Such change management, whether for specialization or reconfiguration of the chemical industry (or even its supply chain) requires an additional effort from companies, according to von Knop (2016) [56]. Baldea et al. (2017) [68]affirmed that process variability is inevitable and coordination between process control and production scheduling is indispensable, utilizing available technology to maximize the production of systems operating in parallel. Infrastructure and facilities compatible with the requirements of the new technology: according to Bogle (2017), computational methods manipulate multiple stages within the chemical industry supply chain and it is necessary to consider the technical constraints of flexible manufacturing at each stage. In this sense, it is necessary to incorporate the capacity to deal with uncertainty in demand and production. To this end, the 
evolution of measurement, transmission and data collection systems should focus on cyber security, data quality and speed of its transmission and use (Yuan, Qin e Zhao, 2017 [64]; CHIANG et al., 2017) [12], [40]. Baldea et al. (2017) [68] further stated that one of the main ideas in the continuous intelligent chemical industry is the connection of operations in parallel.

Reliable adverse event management systems for high risk processes: for Yuan et al. (2017) [40], within the context of Big Data, alarm management, process monitoring, equipment fault diagnosis and human behavior, monitoring must be integrated to achieve a reliable and scalable platform. Natarajan et al. (2012) [33] confirmed that the detection of abnormalities in the process is essential in order for corrective actions to be effective and to maintain the quality of the product, avoid a halt in production and prevent accidents. Li and Liu (2010) [71] provided an example of the logistics of safety management of the chemical industry, which must necessarily be reliable as it deals with flammable, explosive, toxic and corrosive products. For Dai et al. (2016) [83], the goal of new technologies should include the significant reduction of security incidents. The need for a robust fault detection system and the minimization of accidents is a consensus among the authors, since this is the Critical Success Factor most commonly identified in the literature.

Health, safety and environmental assessment models: Squire and Song's (2014) [38] safety statistics suggest that most injuries are the result of violent incidents in the workplace. For Qian et al. (2017) [66], the goal for optimal manufacturing in the industrial chemical process is to promote efficient, green and safe production. Since Industry 4.0 depends on reliable systems, the health, safety and environmental assessment models should be incorporated into the conventional control system (BOGLE, 2017) [58]. Bogle further argued that since chemical processes are often at high risk, it is a key aspect to correct mathematical modeling where health, safety and environmental issues require accurate predictions. Christofides et al. (2007) [14] argued that such measures can also bring great economic benefits, since abnormal situations cause billions of dollars in losses annually. Yuan et al. (2017) pointed out that risk assessment should be the first step in managing abnormal situations. To this end, Baldea et al. (2017) [68] cited the use of intensification of chemical processes in distributed modules as a tool to reduce risks.

Investment in research and development to simplify complex systems and intensify operations, adapting the process in case of unavailability of data: Zhang et al. (2018) considered that Big Data technology offers the opportunity to bypass data unavailability and the difficulty of modeling complex systems through the history of empirical data. Shu et al. (2016) argued that because of the increasing size and complexity of modern chemical processes and the amount of historical data available, historical-based methods show great advances in fault diagnosis. For Ge et al. (2017), the modeling, monitoring, prediction and control of datadriven processes has proven feasible through the use of Machine Learning techniques. Another alternative to circumvent the unavailability of data is the design of distributed production modules, through the intensification of processes. For Baldea et al. (2017) [68], process intensification also allows the transition from batch processes to continuous operation, minimizing process variability and ensuring quality through automated systems.

Reliable data measurement, transmission and data collection systems: for Sun et al. (2017) [84], extracting more knowledge and production data information allows an increase in the understanding of the dynamics of the system and supports the best operation of the equipment efficiently. Montanus (2016) [73] confirmed that this gives rise to opportunities for more efficient and intelligent analyses and better control of industrial systems, and may even cause disruptive changes in the way these systems are designed and used. However, according to Bogle (2017) [58], although a considerable amount of historical trend data is collected in operations, the chemical industry does not incorporate large demand databases directly into its control systems. In this sense, Rathinasabapathy et al. (2016) [34] argued that qualitative models have the advantage of being rigorous even when there is insufficient data or information, replacing advanced instrumentation systems.

Detailed modeling and transcription of systems where possible: correct descriptions of the productive processes are mathematical prerequisites for developing the models (NATARAJAN et al., 2012) [33]. The work of Liu et al. (2017) [62] is an example of how mathematical modeling is capable of decreasing the complexity of variables in the continuous chemical industry, including human factors, equipment, materials, and environmental data. Zhou et al. (2017) [61] saw that the creation of a virtual representation of the physical world, through a digital communication platform was a prerequisite for the deployment of 4.0 technologies. For Windmann et al. (2015) [85], it is fundamental to develop self-learning assistance systems that identify relevant relationships by observing the complex manufacturing processes. The authors believe 
that the Machine Learning technology helps in the detailed modeling of systems in order to automatically detect failures, anomalies and the need for optimization.

\section{Conclusions}

This paper objective was to identify sector-specific difficulties and Critical Success Factors when implementing Industry 4.0 technologies. For this purpose, a comprehensive systematic literature review with content analysis was carried out. This study revealed a greater trend of publications mentioning Big Data, the Internet of Things, Cloud Computing and Cyber-Physical Systems. Also, empirical studies are more frequent in the segments of petrochemical and industrial gas production.

Specific difficulties of the sector can be listed as "model and transcribe complex systems"; "adapt classical control methods to new information systems"; "develop reliable fault response system for high risk processes"; "create health, safety and environmental assessment models"; "plant modifications and production interruptions"; "develop new synthesis processes, intensify operations and adapt products"; "lack of deployment success cases".

Specific Critical Success Factors identified are "minimization of plant modifications or interruptions in the unplanned production process"; "infrastructure and facilities compatible with the requirements of new technologies"; "reliable adverse event management systems for high risk processes"; "health, safety and environmental assessment models"; "investment in research and development to simplify complex systems and intensify operations, adapting the process in case of unavailability of data"; "reliable data measurement, transmission and data collection systems"; and "detailed modeling and transcription of systems where possible".

By analyzing the literature, it is also possible to identify several research gaps and the need for future studies. The research on retrieval and extraction of useful information associated with Big Data, aiming optimization, and control and management, are the topics most widely approached by the publications studied. Several authors agree that future research should focus on data quality assessment methods, extracted from the process and Big Data cleaning techniques. For complex chemical systems, the data are often unavailable. In this sense, it is also necessary to develop models that utilize the history of empirical data to overcome the instability of production systems, as well as Big Data storage systems. More recent publications claim that the development of enhanced process modules is a promising path for the continuous process chemical industry in this new industrial revolution. Research on sensor networks design and updating, communication between machines on larger scales, Machine Learning studies updating and the development of Blockchain technology has barely been explored, despite having great potential for the 4.0 revolution. Fault diagnosis is a recurring theme and the study of its application in the chemical industry is essential, particularly with regards to the origin of failures. New HSE assessment models, the research of the integration of the technologies (before the supply chain) and cybersecurity techniques also should be included in this research agenda. The biggest challenge for the development of Industry 4.0 in the chemical industry is the need for the scientific community to work in a multidisciplinary way, bringing together advances in computer science in data management, production engineering tools, mathematical modeling and technical engineering knowledge of chemical processes.

\section{Acknowledgments}

Funding: This study was financed, in part, by the Coordenação de Aperfeiçoamento de Pessoal de Nível Superior - Brasil (CAPES) - Finance Code 001".

\section{References}

1. S. Tigor, B. Tambunan, B. Christiananta, and D. Rachmawati, "A Conceptual Framework: Organizational Learning, Competencies, and Innovation in Indonesian Digital Startup," doi: 10.18535/ijsrm/v7i10.em04.

2. K. D. Thoben, S. A. Wiesner, and T. Wuest, "'Industrie 4.0' and smart manufacturing-a review of research issues and application examples," Int. J. Autom. Technol., vol. 11, no. 1, pp. 4-16, 2017, doi: 10.20965/ijat.2017.p0004.

3. Campos Martins, T. Edson, and E. Gonçalo, "INDUSTRIA 4.0 E BRASIL: POTENCIALIDADES E LIMITAÇÕES.”2018. 
4. T. H. Nguyen, M. T. Do, and Q. T. Vu, "Relationship between accounting benefits and ERP user satisfaction in the context of the fourth industrial revolution," doi: 10.18535/ijsrm/v8i02.em08.

5. M. Hermann, T. Pentek, and B. Otto, "Design principles for industrie 4.0 scenarios," Proc. Annu. Hawaii Int. Conf. Syst. Sci., vol. 2016-March, pp. 3928-3937, 2016, doi: 10.1109/HICSS.2016.488.

6. P. M. Piccione, "Realistic interplays between data science and chemical engineering in the first quarter of the 21st century, part 2: Dos and don'ts," Chem. Eng. Res. Des., vol. 169, pp. 308-318, May 2021, doi: 10.1016/j.cherd.2021.03.012.

7. H. Shevtsova, N. Shvets, and M. Kasatkina, "How Leading Global Chemical Companies Contribute to Industry 4.0," Oct. 2020, doi: 10.1109/ITMS51158.2020.9259317.

8. P. S. Aithal, "Information Communication and Computation Technology (ICCT) and its Contribution to Universal Technology for Societal Transformation by P. S. Aithal, Shubhrajyotsna Aithal :: SSRN,” 2021. https://papers.ssrn.com/sol3/papers.cfm?abstract_id=3768729 (accessed May 18, 2021).

9. H. Kagermann, W. Wahlster, and J. Helbig, "Securing the future of German manufacturing industry: Recommendations for implementing the strategic initiative INDUSTRIE 4.0," Final Rep. Ind. 4.0 Work. Gr., no. April, pp. 1-84, 2013.

10. A. Kumar, M. Baldea, and T. F. Edgar, "Smart Manufacturing: Application To an Industrial Scale Steam-Methane Reformer," pp. 2-5, 2015.

11. M. Kotynkova, "Re-Industrialization of Europe: Industry4.0 and the Future of Work," Eur. Sci. J., vol. 7881, no. April, pp. 249-256, 2017.

12. L. Chiang, B. Lu, and I. Castillo, "Big data analytics in chemical engineering," Annu. Rev. Chem. Biomol. Eng., vol. 8, no. August, pp. 63-85, 2017, doi: 10.1146/annurev-chembioeng-060816101555.

13. Y. Shu, L. Ming, F. Cheng, Z. Zhang, and J. Zhao, "Abnormal situation management: Challenges and opportunities in the big data era," Comput. Chem. Eng., vol. 91, pp. 104-113, 2016, doi: 10.1016/j.compchemeng.2016.04.011.

14. P. D. Christofides, J. F. Davis, N. H. El-Farra, D. Clark, K. R. D. Harris, and J. N. Gipson, "Smart plant operations: Vision, progress and challenges," AIChE J., vol. 53, no. 11, pp. 2734-2741, Nov. 2007, doi: 10.1002/aic.11320.

15. X. Ji, G. He, J. Xu, and Y. Guo, "Study on the mode of intelligent chemical industry based on cyberphysical system and its implementation," Adv. Eng. Softw., vol. 99, pp. 18-26, 2016, doi: 10.1016/j.advengsoft.2016.04.010.

16. R. Schlögl, “Catalysis 4.0," ChemCatChem, vol. 9, no. 4, pp. 533-541, 2017, doi: 10.1002/cctc. 201700026.

17. J. Vinuto, “A amostragem em bola de neve na pesquisa qualitativa," Tematicas, vol. 22, no. 44, pp. 203-220, Dec. 2014, doi: 10.20396/tematicas.v22i44.10977.

18. B. E. Ydstie, "New vistas for process control: Integrating physics and communication networks," AIChE J., vol. 48, no. 3, pp. 422-426, 2002, doi: 10.1002/aic.690480302.

19. I. Grossmann, "Enterprise-wide optimization: A new frontier in process systems engineering," AIChE J., vol. 51, no. 7, pp. 1846-1857, 2005, doi: 10.1002/aic.10617.

20. J. Edgar, T; Davis, "SMART PROCESS MANUFACTURING - A VISION OF THE FUTURE," 2009.

21. J. Davis, T. Edgar, J. Porter, J. Bernaden, and M. Sarli, "Smart manufacturing, manufacturing intelligence and demand-dynamic performance," Comput. Chem. Eng., vol. 47, pp. 145-156, 2012, doi: 10.1016/j.compchemeng.2012.06.037.

22. J. Davis and D. Swink, "Smart Manufacturing as a Real-Time Networked Enterprise and a MarketDriven Innovation Platform Role/Viewpoint of panelist or organization," Smart Manuf. Leadersh. Coalit., p. 5, 2012, [Online]. Available: https://smartmanufacturingcoalition.org/sites/default/files/smlc_sm-realtime_networked_enterprise_1.pdf.

23. J. Davis, T. Edgar, R. Graybill, P. Korambath, B. Schott, D. Swink, J. Wang, and J. Wetzel, "Smart Manufacturing" Annual Review of Chemical and Biomolecular Engineering., vol. 6 n. 1, 2015, doi:10.1146/annurev-chembioeng-061114-123255 
24. Q. Hao, F. Zhang, Z. Liu, and L. Qin, "Design of Chemical Industrial Park Integrated Information Management Platform Based on Cloud Computing and IOT (The Internet of Things) Technologies," Int. J. Smart Home, vol. 9, no. 4, pp. 35-46, Apr. 2015, doi: 10.14257/ijsh.2015.9.4.04.

25. S. Van Thieven, A. Cliton, M. Mahto, and B. Sniderman, "chemicals industry Catalyzing transformation," Deloitte Univeristy Press, pp. 1-24, 2016.

26. K. Inaba, "The Common Integration The Group Operation of Petrochemical Complexes in Japan," $J$. Innov. Sustain. RISUS ISSN 2179-3565, vol. 5, no. 1, p. 94, 2014, doi: 10.24212/21793565.2014v5i2p94-102.

27. M. V. García, E. Irisarri, F. Pérez, E. Estévez, and M. Marcos, "An Open CPPS Automation Architecture based on IEC-61499 over OPC-UA for flexible manufacturing in Oil\&Gas Industry," IFAC-PapersOnLine, vol. 50, no. 1, pp. 1231-1238, 2017, doi: 10.1016/j.ifacol.2017.08.347.

28. C. Khare and S. T. Chin, "Potential for data analytics opportunities in SMART Chemical industry," Chim. Oggi/Chemistry Today, vol. 35, no. 2, pp. 60-61, 2017.

29. T. Wang, T. Li, Y. Xia, Z. Zhang, and S. Jin, "Risk Assessment and Online Forewarning of Oil \& Gas Storage and Transportation Facilities Based on Data Mining," Procedia Comput. Sci., vol. 112, pp. 1945-1953, 2017, doi: 10.1016/j.procs.2017.08.052.

30. Q. P. He, J. Wang, D. Shah, and N. Vahdat, "Statistical Process Monitoring for IoT-Enabled Cybermanufacturing: Opportunities and Challenges," IFAC-PapersOnLine, vol. 50, no. 1, pp. 14946-14951, 2017, doi: 10.1016/j.ifacol.2017.08.2546.

31. G. Martin, "Wireless networks improve refinery operation.," Hydrocarb. Process., vol. 88, no. 3, pp. 29-32, 2009.

32. R.-F. Chang, C.-W. Chang, K.-H. Tseng, C.-L. Chiang, W.-S. Kao, and W.-J. Chen, "Structural planning and implementation of a microprocessor-based human-machine interface in a steamexplosion process application," Comput. Stand. Interfaces, vol. 33, no. 3, pp. 232-248, Mar. 2011, doi: 10.1016/j.csi.2010.05.001.

33. S. Natarajan, K. Ghosh, and R. Srinivasan, "An ontology for distributed process supervision of largescale chemical plants," Comput. Chem. Eng., vol. 46, pp. 124-140, 2012, doi: 10.1016/j.compchemeng.2012.06.009.

34. R. Rathinasabapathy, M. J. Elsass, J. R. Josephson, and J. F. Davis, "A smart manufacturing methodology for real time chemical process diagnosis using causal link assessment," AIChE J., vol. 62, no. 9, pp. 3420-3431, Sep. 2016, doi: 10.1002/aic.15403.

35. J.-P. Belaud, S. Negny, F. Dupros, D. Michéa, and B. Vautrin, "Collaborative simulation and scientific big data analysis: Illustration for sustainability in natural hazards management and chemical process engineering," Comput. Ind., vol. 65, no. 3, pp. 521-535, Apr. 2014, doi: 10.1016/j.compind.2014.01.009.

36. S. J. Qin, "Process data analytics in the era of big data," AIChE J., vol. 60, no. 9, pp. 3092-3100, Sep. 2014, doi: 10.1002/aic.14523.

37. R. Blackburn, K. Lurz, B. Priese, R. Göb, and I.-L. Darkow, "A predictive analytics approach for demand forecasting in the process industry," Int. Trans. Oper. Res., vol. 22, no. 3, pp. 407-428, May 2015, doi: 10.1111/itor.12122.

38. R. Squire and H. Song, "Cyber-physical systems opportunities in the chemical industry: A security and emergency management example," Process Saf. Prog., vol. 33, no. 4, pp. 329-332, Dec. 2014, doi: $10.1002 /$ prs. 11676 .

39. Z. Zhang et al., "A strategy for enhancing the operational agility of petroleum refinery plant using case based fuzzy reasoning method," Comput. Chem. Eng., vol. 111, pp. 27-36, 2018, doi: 10.1016/j.compchemeng.2017.12.021.

40. Z. Yuan, W. Qin, and J. Zhao, "Smart Manufacturing for the Oil Refining and Petrochemical Industry," Engineering, vol. 3, no. 2, pp. 179-182, 2017, doi: 10.1016/J.ENG.2017.02.012.

41. H. Hassani, E. S. Silva, and A. M. Al Kaabi, "The role of innovation and technology in sustaining the petroleum and petrochemical industry," Technol. Forecast. Soc. Change, vol. 119, pp. 1-17, 2017, doi: 10.1016/j.techfore.2017.03.003.

42. H. Hamzeh, “Application of Big Data in Petroleum Idustry,” Big Data, no. February, pp. 1189-1208, 2016.

43. P. Korambath et al., "Deploying kepler workflows as services on a cloud infrastructure for smart 
manufacturing," Procedia Comput. Sci., vol. 29, pp. 2254-2259, 2014, doi: 10.1016/j.procs.2014.05.210.

44. Kumar, A., "Model based Operation of Industrial Steam Methane Reformers using Large Scale Sensor Data," (PhD Thesis). The University of Texas at Austin, Austin. 2016.

45. A. Kumar, M. Baldea, and T. F. Edgar, "On optimal sensing and actuation design for an industrial scale steam methane reformer furnace." AIChE Journal., vol. 62, n. 9, p. 3225-3237, 2016a, doi.org/10.1002/aic.15333

46. A. Kumar, M. Baldea, and T. F. Edgar, "Real-time optimization of an industrial steam-methane reformer under distributed sensing," Control Eng. Pract., vol. 54, pp. 140-153, 2016b, doi: 10.1016/j.conengprac.2016.05.010.

47. A. Kumar, M. Baldea, and T. F. Edgar, "A physics-based model for industrial steam-methane reformer optimization with non-uniform temperature field," Computers \& Chemical Engineering, vol. 105, p. 224-236, 2016c, doi.org/10.1016/j.compchemeng.2017.01.002

48. A. Kumar, M. Baldea, and T. F. Edgar, "Multi-resolution model of an industrial hydrogen plant for plantwide operational optimization with non-uniform steam-methane reformer temperature field," Computers \& Chemical Engineering, vol. 107, p. 271-283, 2016d, doi.org/10.1016/j.compchemeng.2017.02.040

49. A. Kumar, M. Baldea, and T. F. Edgar, "Smart Manufacturing: Application to an Industrial Scale Steam-Methane Reformer. Proceedings of FOCAPO/CPC. University of Texas at Austin. 2017.

50. P. Korambath, J., Wang, A. Kumar, J. Davis, R. Graybill, B. Schott, M. Baldea "A smart manufacturing use case: Furnace temperature balancing in steam methane reforming process via kepler workflows," Procedia Computer Science, vol. 80, pp. 680-689, 2016.

51. M. Pan et al., "Applying Industry 4.0 to the Jurong Island Eco-industrial Park," Energy Procedia, vol. 75, pp. 1536-1541, Aug. 2015, doi: 10.1016/j.egypro.2015.07.313.

52. M. J. Kleinelanghorst et al., "J-Park Simulator: Roadmap to Smart Eco-Industrial Parks," Proc. Second Int. Conf. Internet things, Data Cloud Comput. - ICC '17, no. 174, pp. 1-10, 2017, [Online]. Available: http://dl.acm.org/citation.cfm?doid=3018896.3025155.

53. J. J. Sikorski, J. Haughton, and M. Kraft, "Blockchain technology in the chemical industry: Machineto-machine electricity market," Appl. Energy, vol. 195, pp. 234-246, 2017, doi: 10.1016/j.apenergy.2017.03.039.

54. S. Natarajan and R. Srinivasan, "Implementation of multi agents based system for process supervision in large-scale chemical plants," Comput. Chem. Eng., vol. 60, pp. 182-196, Jan. 2014, doi: 10.1016/j.compchemeng.2013.08.012.

55. M. Helu, K. Morris, K. Jung, K. Lyons, and S. Leong, "Identifying performance assurance challenges for smart manufacturing," Manuf. Lett., vol. 6, pp. 1-4, 2015, doi: 10.1016/j.mfglet.2015.11.001.

56. J. von Kbop, "Chemistry 4.0 challenges and solutions for the digital transformation," Croatica Chemica Acta, vol. 89, n. 4, p. 397-402, 2016.

57. A. Gezdur and J. Bhattacharjya, "Digitization in the oil and gas industry: Challenges and opportunities for supply chain partners," IFIP Adv. Inf. Commun. Technol., vol. 506, no. August, pp. 97-103, 2017, doi: 10.1007/978-3-319-65151-4_9.

58. I. D. L. Bogle, "A Perspective on Smart Process Manufacturing Research Challenges for Process Systems Engineers," Engineering, vol. 3, no. 2, pp. 161-165, 2017, doi: 10.1016/J.ENG.2017.02.003.

59. A. Reitze, N. Jürgensmeyer, S. Lier, M. Kohnke, J. Riese, and M. Grünewald, "Roadmap for a Smart Factory: A Modular, Intelligent Concept for the Production of Specialty Chemicals," Angew. Chemie - Int. Ed., vol. 57, no. 16, pp. 4242-4247, 2018, doi: 10.1002/anie.201711571.

60. A. J. Isaksson, I. Harjunkoski, and G. Sand, "The impact of digitalization on the future of control and operations," Comput. Chem. Eng., vol. 114, pp. 122-129, 2018, doi: 10.1016/j.compchemeng.2017.10.037.

61. L. Zhou et al., "Towards an ontological infrastructure for chemical process simulation and optimization in the context of eco-industrial parks," Appl. Energy, vol. 204, no. 181, pp. 1284-1298, 2017, doi: 10.1016/j.apenergy.2017.05.002.

62. W. Liu, K. Wei, J. Xu, and X. Ji, "A Hybrid Algorithm for the Reliability Evaluation Models of 
Chemical Systems," Qual. Reliab. Eng. Int., vol. 33, no. 7, pp. 1337-1349, 2017, doi: 10.1002/qre.2108.

63. G. Yang, "Data acquisition technology of chemical equipment based on wireless sensor network," Chem. Eng. Trans., vol. 66, pp. 943-948, 2018, doi: 10.3303/CET1866158.

64. H. Yan, Q. Hua, Y. Wang, W. Wei, and M. Imran, "Cloud robotics in Smart Manufacturing Environments: Challenges and countermeasures," Comput. Electr. Eng., vol. 63, pp. 56-65, 2017, doi: 10.1016/j.compeleceng.2017.05.024.

65. M. JOLY, D. ODLOAK, M. MIYAKE, B. C. MENEZES, and J. D. KELLY, "Refinery production scheduling toward Industry 4.0," Front. Eng. Manag., vol. 0, no. 0, p. 0, 2018, doi: 10.15302/j-fem2017024.

66. F. Qian, W. Zhong, and W. Du, "Fundamental Theories and Key Technologies for Smart and Optimal Manufacturing in the Process Industry," Engineering, vol. 3, no. 2, pp. 154-160, 2017, doi: 10.1016/J.ENG.2017.02.011.

67. V. de. Leeuw, "Industrie 4.0 in the Chemical Industry.," ARC Insights.

68. M. Baldea, T. F. Edgar, B. L. Stanley, and A. A. Kiss, "Modular manufacturing processes: Status, challenges, and opportunities," AIChE J., vol. 63, no. 10, pp. 4262-4272, Oct. 2017, doi: 10.1002/aic.15872.

69. A. Kusiak, "Smart manufacturing," Int. J. Prod. Res., vol. 56, no. 1-2, pp. 508-517, 2018, doi: 10.1080/00207543.2017.1351644.

70. S. V. Mohan and R. Katakojwala, "The circular chemistry conceptual framework: A way forward to sustainability in industry 4.0," Current Opinion in Green and Sustainable Chemistry, vol. 28. Elsevier B.V., p. 100434, Apr. 01, 2021, doi: 10.1016/j.cogsc.2020.100434.

71. H. H. Li and Y. H. Liu, "A Study of the Real-Time Monitoring System for Chemical Logistics Based on Internet of Things," Conf. Web Based Bus. Manag. Vols 1-2, no. April 2004, pp. 337-340\r1271, 2010.

72. V. Venkatasubramanian, "DROWNING IN DATA: Informatics and modeling challenges in a datarich networked world," AIChE J., vol. 55, no. 1, pp. 2-8, Jan. 2009, doi: 10.1002/aic.11756.

73. M. Montanus, "Business Models for Industry 4.0 - Developing a Framework To Determine and Assess Impacts on Business Models in the Dutch Oil and Gas Industry," Delft Univ. Technol., p. 10, 2016, [Online]. Available: repository.tudelft.nl.

74. R. D. Colauto, C. M. Gonçalves, I. M. Beuren, and N. Dos Santos, "The Critical Success Factors As Support Of A System Of Competitive Intelligence: The Case Of One Brazilian Company.," Rev. Adm. Mackenzie, vol. 5, no. 2, pp. 119-146, 2004.

75. N. Ivezic, B. Kulvatunyou, and V. Srinivasan, "On architecting and composing through-life engineering information services to enable smart manufacturing," Procedia CIRP, vol. 22, no. 1, pp. 45-52, 2014, doi: 10.1016/j.procir.2014.07.004.

76. M. Helu and T. Hedberg, "Enabling Smart Manufacturing Research and Development using a Product Lifecycle Test Bed," Procedia Manuf., vol. 1, no. Wolf 2009, pp. 86-97, 2015, doi: 10.1016/j.promfg.2015.09.066.

77. K. Jung, K. C. Morris, K. W. Lyons, S. Leong, and H. Cho, "Mapping strategic goals and operational performance metrics for smart manufacturing systems," Procedia Comput. Sci., vol. 44, no. C, pp. 184-193, 2015, doi: 10.1016/j.procs.2015.03.051.

78. H. Luo, K. Wang, X. T. R. Kong, S. Lu, and T. Qu, "Synchronized production and logistics via ubiquitous computing technology," Robot. Comput. Integr. Manuf., vol. 45, pp. 99-115, 2017, doi: 10.1016/j.rcim.2016.01.008.

79. Y. Lu, "Industry 4.0: A survey on technologies, applications and open research issues," J. Ind. Inf. Integr., vol. 6, pp. 1-10, 2017, doi: 10.1016/j.jii.2017.04.005.

80. P. O’Donovan, K. Leahy, K. Bruton, and D. T. J. O'Sullivan, "An industrial big data pipeline for data-driven analytics maintenance applications in large-scale smart manufacturing facilities," J. Big Data, vol. 2, no. 1, pp. 1-26, 2015, doi: 10.1186/s40537-015-0034-z.

81. S. S. Choi, B. H. Kim, and S. Do Noh, "A diagnosis and evaluation method for strategic planning and systematic design of a virtual factory in smart manufacturing systems," Int. J. Precis. Eng. Manuf., vol. 16, no. 6, pp. 1107-1115, 2015, doi: 10.1007/s12541-015-0143-9.

82. D. Li, "Perspective for smart factory in petrochemical industry," Comput. Chem. Eng., vol. 91, pp. 
136-148, 2016, doi: 10.1016/j.compchemeng.2016.03.006.

83. Y. Dai, H. Wang, F. Khan, and J. Zhao, "Abnormal situation management for smart chemical process operation," Curr. Opin. Chem. Eng., vol. 14, pp. 49-55, 2016, doi: 10.1016/j.coche.2016.07.009.

84. B. Sun, S. L. Jämsä-Jounela, Y. Todorov, L. E. Olivier, and I. K. Craig, "Perspective for equipment automation in process industries," IFAC-PapersOnLine, vol. 50, no. 2, pp. 65-70, 2017, doi: 10.1016/j.ifacol.2017.12.012.

85. S. Windmann et al., "Big data analysis of manufacturing processes," J. Phys. Conf. Ser., vol. 659, no. 1 , 2015, doi: 10.1088/1742-6596/659/1/012055. 